\title{
The role of small intestinal bacterial overgrowth, intestinal permeability, endotoxaemia, and tumour necrosis factor $\alpha$ in the pathogenesis of non-alcoholic steatohepatitis
}

\author{
A J Wigg, I C Roberts-Thomson, R B Dymock, P J McCarthy, R H Grose, A G Cummins
}

Department of Gastroenterology, Queen Elizabeth Hospital, Adelaide, South Australia, Australia

A J Wigg

I C Roberts-Thomson

R H Grose

A G Cummins

Department of Histopathology, Queen Elizabeth Hospital, Adelaide, South Australia, Australia R B Dymock

Department of Biochemistry, Repatriation General Hospital, Adelaide, South Australia,

Australia

P J McCarthy

Correspondence to: A J Wigg, Unit of Gastroenterology and Hepatology, Flinders Medical Centre, Bedford Park, 5042, South Australia, Australia.

alan.wigg@flinders.edu.au

Accepted for publication 18 July 2000

\begin{abstract}
Background-Small intestinal bacterial overgrowth may contribute to the development of non-alcoholic steatohepatitis, perhaps by increasing intestinal permeability and promoting the absorption of endotoxin or other enteric bacterial products.

Aims-To investigate the prevalence of small intestinal bacterial overgrowth, increased intestinal permeability, elevated endotoxin, and tumour necrosis factor $\alpha$ (TNF- $\alpha$ ) levels in patients with nonalcoholic steatohepatitis and in control subjects.

Patients and methods-Twenty two patients with non-alcoholic steatohepatitis and 23 control subjects were studied. Small intestinal bacterial overgrowth was assessed by a combined ${ }^{14} \mathrm{C}-\mathrm{D}-\mathrm{xylose}$ and lactulose breath test. Intestinal permeability was assessed by a dual lactuloserhamnose sugar test. Serum endotoxin levels were determined using the limulus amoebocyte lysate assay and TNF- $\alpha$ levels using an ELISA.

Results-Small intestinal bacterial overgrowth was present in $50 \%$ of patients with non-alcoholic steatosis and $22 \%$ of control subjects $(p=0.048)$. Mean TNF- $\alpha$ levels in non-alcoholic steatohepatitis patients and control subjects were 14.2 and $7.5 \mathrm{pg} / \mathrm{ml}$, respectively $(p=0.001)$. Intestinal permeability and serum endotoxin levels were similar in the two groups.

Conclusions-Patients with non-alcoholic steatohepatitis have a higher prevalence of small intestinal bacterial overgrowth, as assessed by the ${ }^{14} \mathrm{C}-\mathrm{D}$-xylose-lactulose breath test, and higher TNF- $\alpha$ levels in comparison with control subjects. This is not accompanied by increased intestinal permeability or elevated endotoxin levels. (Gut 2001;48:206-211)
\end{abstract}

Keywords: non-alcoholic steatohepatitis; small intestinal bacterial overgrowth; intestinal permeability; endotoxin; tumour necrosis factor $\alpha$

The pathogenesis of non-alcoholic steatohepatitis (NASH) remains unclear. Several observations have suggested that small intestinal bacterial overgrowth (SIBO) may play a role in NASH. Firstly, NASH was encountered as a common complication of jejunoileal bypass surgery for morbid obesity during the 1980s and could be reversed by treatment with metronidazole. ${ }^{1}$ Secondly, several patients with jejunoileal bypass associated NASH required liver transplantation and NASH recurred rapidly following transplantation, particularly in patients who did not have the jejunoileal bypass reversed at the time of transplantation. ${ }^{2}$ Thirdly, NASH has been reported in one individual with jejunal diverticulosis and SIBO diagnosed by a ${ }^{14} \mathrm{CO}_{2}$ bile acid breath test. ${ }^{3}$ Finally, various rat models of SIBO have been associated with liver lesions similar to $\mathrm{NASH}^{4}$ that improved following antibiotics. ${ }^{67}$ Despite these observations the prevalence of SIBO has not been investigated in patients with NASH.

SIBO could increase intestinal permeability and absorption of endotoxin. Considerable evidence already exists demonstrating that endotoxin can induce steatohepatitis, mediated chiefly via the cytokine tumour necrosis factor $\alpha(\mathrm{TNF}-\alpha)$. In alcoholic liver disease, which shares histological similarities to NASH, endotoxin induced stimulation of Kupffer cells has been proposed as an important initiating event leading to the production of proinflammatory cytokines and oxygen free radicals. ${ }^{89}$ Yang and coworkers have suggested that systemic endotoxaemia contributes to $\mathrm{TNF}-\alpha$ production and steatohepatitis in genetically obese rats. ${ }^{10} \mathrm{It}$ seems plausible therefore that gut derived endotoxin, perhaps from SIBO, is important in the pathogenesis of NASH via Kupffer cell stimulation and TNF- $\alpha$ production. To our knowledge however no human study of NASH patients has measured intestinal permeability, endotoxin, or TNF- $\alpha$ levels.

The aim of this study therefore was to determine the prevalence of SIBO in a series of NASH patients and to assess if this is accompanied by increased intestinal permeability or elevated serum levels of endotoxin and TNF- $\alpha$.

Subjects and methods

SUBJECTS

Twenty two patients with NASH were studied. They were consecutive cases diagnosed in our gastroenterology clinic between 1994 and 1997. Three diagnostic criteria were used for

Abbreviations used in this paper: $\mathrm{NASH}$, non-alcoholic steatohepatitis; SIBO, small intestinal bacterial overgrowth; TNF- $\alpha$, tumour necrosis factor $\alpha ; \mathrm{L} / \mathrm{R}$ ratio, lactulose/rhamnose permeability ratio; BMI, body mass index. 
patient inclusion. Firstly, histological diagnosis was made with liver biopsy. Histological sections from each liver biopsy were stained with haematoxylin-eosin, Perls' Prussian blue, and Gordon and Sweet's reticulin and were interpreted by a single experienced histopathologist (RBD). The minima histological criteria were the presence of macrovesicular steatosis and inflammation. Hepatic fibrosis and Mallory's bodies were not considered essential for the diagnosis. Three patients did not consent to liver biopsy. These patients had fatty infiltration on ultrasound or CT scan of the liver, abnormal liver function tests, and otherwise fulfilled the other inclusion criteria.

The second inclusion criterion was no significant alcohol consumption, defined as no greater than $20 \mathrm{~g}$ of alcohol per day. Alcohol history was taken by two physicians on two different occasions and confirmed with family members where possible. Patients with detectable blood alcohol on a fasting morning specimen or an elevated mean corpuscular volume were excluded. The mean alcohol consumption of NASH patients was $14 \mathrm{~g}$ per week; 12 of the 22 patients drank no alcohol.

The third criterion was the absence of other relevant liver diseases. All patients were negative for hepatitis B surface antigen and antibody to hepatitis C. No patient had antimitochondrial antibody or significantly elevated titres of antinuclear or antismooth muscle antibody.

Control subjects were age and sex matched with NASH patients. All control subjects had normal liver function tests and no history of liver disease. They were made up of volunteers and ambulatory outpatients with minor gastrointestinal complaints.

In addition, a drug history, recording of height and weight for calculation of body mass index, and bloods for triglyceride and cholesterol levels were obtained for all NASH patients and control subjects. Fasting glucose levels and immunoglobulins were also assessed in NASH patients and random glucose levels in control subjects.

${ }^{14} \mathrm{C}-\mathrm{D}$-XYLOSE AND LACTULOSE BREATH TEST

Twenty two NASH patients and 23 control subjects were studied by a ${ }^{14} \mathrm{C}$-D-xylose and lactulose breath test. This combined breath test was designed to improve the specificity of the ${ }^{14} \mathrm{C}$-D-xylose breath test which has been associated with a significant false positive rate. ${ }^{11}{ }^{12}$ This may be due to rapid colonic transit and catabolism of unabsorbed ${ }^{14} \mathrm{C}$-D-xylose, resulting in early ${ }^{14} \mathrm{CO}_{2}$ expiration and the erroneous diagnosis of SIBO. The combined breath test has been designed to overcome this problem. Lactulose, which requires much greater concentrations of bacteria to produce an observed $\mathrm{H}_{2} / \mathrm{CH}_{4}$ rise in breath, acts as an internal transit marker of colonic bacterial catabolism in individuals both with and without SIBO. To help validate this test, we performed both ${ }^{14} \mathrm{C}$ D-xylose and lactulose breath tests on 11 of our $\mathrm{NASH}$ patients. Nine $(82 \%)$ of the ${ }^{14} \mathrm{C}-\mathrm{D}-$ xylose tests were positive whereas only four $(36 \%)$ of the ${ }^{14} \mathrm{C}$-D-xylose and lactulose tests were normal. In a study population in which the majority had no clear predisposing syndromes for SIBO (four of the 11 had diabetes), we believe that the lower number of positive tests in the ${ }^{14} \mathrm{C}$-D-xylose and lactulose tests reflects the greater specificity of this test.

We did not use culture of jejunal aspirates to diagnose SIBO because this test has not been firmly established as a gold standard..$^{13}$ Ethical and logistical issues also prevented the use of jejunal culture in this case control study.

To perform the test, subjects ingested $1 \mu \mathrm{Ci}$ of radiolabelled ${ }^{14} \mathrm{C}-\mathrm{D}$-xylose together with $6.68 \mathrm{~g}(10 \mathrm{ml})$ of lactulose made up to a volume of $100 \mathrm{ml}$ with distilled water. Bacterial catabolic products of ${ }^{14} \mathrm{C}$-D-xylose $\left({ }^{14} \mathrm{CO}_{2}\right)$ and lactulose $\left(\mathrm{CH}_{4}\right.$ and $\left.\mathrm{H}_{2}\right)$ were measured every 30 minutes from ingestion for a minimum of four hours. Breath tests were interpreted as positive for SIBO if significant ${ }^{14} \mathrm{CO}_{2}\left(>70 \times 10^{-6}\right.$ DPM) was expired before the colonic $\mathrm{H}_{2}$ and $\mathrm{CH}_{4}$ rise, or if a double $\mathrm{H}_{2}$ and $\mathrm{CH}_{4}$ peak occurred. Breath tests were interpreted as negative if a significant ${ }^{14} \mathrm{CO}_{2}$ rise was detected simultaneously with the colonic $\mathrm{H}_{2}$ and $\mathrm{CH}_{4}$ rise. Equivocal tests, where there was no significant $\mathrm{H}_{2}$ and $\mathrm{CH}_{4}$ rise (>10 PPM), were recorded as negative. To prevent disturbances of colonic flora, antibiotics, colonoscopy, barium enema, or other bowel washouts were avoided for one month prior to testing. Patients were also required to comply with a low residue diet the day before the test and not to smoke within two hours of the test to prevent high basal levels of $\mathrm{H}_{2}$.

An estimate of oral-caecal or small intestinal transit time was calculated, where possible, by observing the time taken from ingestion of lactulose to the appearance of the $\mathrm{H}_{2}$ and $\mathrm{CH}_{4}$ peak, indicating colonic catabolism of lactulose.

LACTULOSE-RHAMNOSE INTESTINAL

PERMEABILITY TEST

Eighteen NASH patients and 20 control subjects completed permeability testing. Subjects fasted overnight and emptied their bladder before drinking $100 \mathrm{ml}$ of a hypertonic solution (1500 mosmol) containing $1.0 \mathrm{~g}$ $\alpha$-L-rhamnose (R-3875, Sigma, St Louis, Missouri, USA), $5.0 \mathrm{~g}$ lactulose (Duphalac, $67 \% \mathrm{w} / \mathrm{v}$ syrup, Dulphar BV, Holland), and $22.6 \mathrm{~g}$ of glucose as an osmotic filler. Urine was collected for the next five hours. Subjects were encouraged to drink water after the first 30 minutes and could eat after three hours. Urine volume was measured and the concentration of urinary lactulose and rhamnose determined using a modified HPLC method as described by Miki and colleagues. ${ }^{14}$ Intestinal permeability was expressed as the excretion ratio of urinary lactulose to rhamnose with each expressed as a percentage of the ingested dose.

ENDOTOXIN ASSAY

Endotoxin was measured in all NASH patients and control subjects. Sera were diluted 1:10 and heated $\left(70^{\circ} \mathrm{C}\right)$ for five minutes to remove non-specific inhibitors of endotoxin. The assay was performed using the Bio Whittaker (Bio 
Table 1 Clinical and biochemical variables (mean (SD)) for patients with non-alcoholic steatohepatitis $(\mathrm{NASH})(n=22)$ and controls $(n=23)$

\begin{tabular}{|c|c|c|c|}
\hline Variable (normal range) & NASH patients & Control subjects & $p$ Value \\
\hline Age & $54 \quad(17)$ & $50 \quad(16)$ & 0.4 \\
\hline $\operatorname{BMI}\left(19-25 \mathrm{~kg} / \mathrm{m}^{2}\right)$ & $30 \quad(6)$ & $24 \quad(5)$ & 0.002 \\
\hline Cholesterol $(<5.5 \mathrm{mmol} / \mathrm{l})$ & $5.7(1.3)$ & $5.4(0.9)$ & 0.3 \\
\hline Triglyceride $(0.7-2.1 \mathrm{mmol} / \mathrm{l})$ & $2.4(2.1)$ & $1.6(1.0)$ & 0.1 \\
\hline Fasting glucose $(3-5.4 \mathrm{mmol} / \mathrm{l})$ & $6 \quad(1.9)$ & & \\
\hline Random glucose $(3-7.7 \mathrm{mmol} / \mathrm{l})$ & & $5.3(1)$ & \\
\hline AST $(0-45 \mathrm{U} / \mathrm{l})$ & $124 \quad(159)$ & $19 \quad(5)$ & 0.003 \\
\hline ALT $(0-55 \mathrm{U} / 1)$ & 153 (161) & $18 \quad(9)$ & $<0.001$ \\
\hline AST/ALT ratio & $0.8(0.4)$ & $1.3(0.6)$ & 0.008 \\
\hline GGT $(0-55 \mathrm{U} / 1)$ & 125 (133) & 19 (10) & $<0.001$ \\
\hline $\operatorname{ALP}(30-110 \mathrm{U} / 1)$ & 118 & $70 \quad(23)$ & 0.03 \\
\hline Bilirubin $(1-20 \mu \mathrm{mol} / \mathrm{l})$ & $18 \quad(23)$ & 11 (5) & 0.2 \\
\hline
\end{tabular}

AST, aspartate aminotransferase; ALT, alanine aminotransferase; GGT, gamma glutamyltransferase; ALP, alkaline phosphate.

Whittaker, Inc, Walkersville, USA) QCL-1000 chromogenic limulus amoebocyte lysate test kit, using the manufacturer's instructions.

TNF- $\alpha$ ASSAY

TNF- $\alpha$ was measured in the sera of 21 NASH patients and 22 control subjects using an ELISA (Quantikine human TNF- $\alpha$ assay, R\&D Systems, Inc, Minneapolis, USA) according to the manufacturer's instructions.

STATISTICS

Statistical analysis was carried out using Statistica 5.0 for Windows software (Statsoft, Inc, Tulsa, USA). Comparisons between groups for parametric data were performed using the Student's $t$ test. Comparisons between groups for non-parametric data were performed using $\chi^{2}$ analysis. Differences were considered statistically significant for $\mathrm{p}<0.05$.

ETHICS

Informed consent was obtained from all subjects. The study was approved by the human ethics committee of the Queen Elizabeth Hospital.

\section{Results}

CLINICAL AND BIOCHEMICAL CHARACTERISTICS OF NASH PATIENTS AND CONTROL SUBJECTS Patient characteristics are shown in table 1. Patient and control groups were well matched for age and sex. The male:female ratio for NASH patients was 8:14 and 7:16 for the control subjects. NASH patients were significantly more obese than control subjects (mean body mass index (BMI) $\left.30 v 24 \mathrm{~kg} / \mathrm{m}^{2} ; \mathrm{p}=0.002\right)$. In addition, the proportion of obese NASH patients was significantly higher than that of obese control subjects $(77 \% v 27 \% ; \mathrm{p}=0.002)$.

Five $(23 \%)$ of the NASH group had known type 2 diabetes mellitus. In addition, a further four NASH patients had glucose intolerance diagnosed on the basis of fasting glucose levels of $5.5-7.7 \mathrm{mmol} / 1$. One (4\%) control subject had known type 2 diabetes mellitus and no further diabetes or glucose intolerance was discovered following random glucose measurement. The prevalence of type 2 diabetes mellitus was significantly higher in NASH patients $(\mathrm{p}=0.03)$.

The prevalence of hyperlipidaemia, defined as serum triglyceride $>2.1 \mathrm{mmol} / 1$ and/or cholesterol $>5.5 \mathrm{mmol} / \mathrm{l}$, was not significantly different between NASH patients and control subjects $(59 \%$ v $43 \%$; $\mathrm{p}=0.3)$.

\section{FIBROTIC SEVERITY OF NASH PATIENTS}

Twelve of 19 (63\%) NASH patients who had liver biopsy demonstrated fibrosis. The mean Scheuer grade for fibrosis was 0.8 (SD 0.8, range $0-2$ ).

${ }^{14} \mathrm{C}-\mathrm{D}$-XYLOSE AND LACTULOSE BREATH TESTS All data for breath tests and small intestinal transit time are presented in tables 2 and 3 . Eleven $(50 \%)$ NASH patients and five $(22 \%)$ control subjects had positive ${ }^{14} \mathrm{C}$-D-xylose and lactulose breath tests indicating SIBO $\left(\chi^{2}=3.92, \mathrm{p}=0.048,95 \% \mathrm{CI}\right.$ for the difference between proportions $3.4-57.9 \%$ ).

Table $2{ }^{14} C-D-x y l o s e$ and lactulose breath tests, endotoxin levels, intestinal permeability, tumour necrosis factor $a(T N F-a)$ levels, small intestinal transit time, and diabetes prevalence in patients with non-alcoholic steatohepatitis (NASH)

\begin{tabular}{|c|c|c|c|c|c|c|}
\hline Patient No & $\begin{array}{l}{ }^{14} C-D-x y l o s e+ \\
\text { lactulose breath test }\end{array}$ & $\begin{array}{l}\text { Endotoxin level } \\
(E U / \mathrm{ml})\end{array}$ & $\begin{array}{l}\text { Intestinal } \\
\text { permeability (L/R } \\
\text { ratio) }\end{array}$ & $\begin{array}{l}T N F-a \\
(p g / m l)\end{array}$ & $\begin{array}{l}\text { Small intestinal transit } \\
\text { time (minutes) }\end{array}$ & $\begin{array}{l}\text { Diabetes } \\
\text { (yes/no/gi) }\end{array}$ \\
\hline 1 & Positive & 1.0 & & 5.8 & 180 & No \\
\hline 2 & Negative & 1.2 & 0.13 & 6.6 & & No \\
\hline 3 & Positive & 0.9 & 0.19 & 27 & 240 & gi \\
\hline 4 & Negative & 1.0 & 0.06 & 14.3 & 180 & gi \\
\hline 5 & Positive & 1.4 & 0.33 & 10.8 & 150 & No \\
\hline 6 & Negative & 1.2 & & 22.3 & & No \\
\hline 7 & Negative & 0.9 & 0.09 & 5.4 & & gi \\
\hline 8 & Negative & 1.0 & 0.05 & 14.3 & & No \\
\hline 9 & Positive & 0.7 & 0.5 & 20 & 210 & Yes \\
\hline 10 & Positive & 0.8 & & 8.9 & 210 & No \\
\hline 11 & Negative & 1.2 & 0.36 & 18.9 & 210 & No \\
\hline 12 & Positive & 0.9 & 0.10 & 7.3 & 210 & gi \\
\hline 13 & Negative & 1.5 & 0.05 & 20.8 & 120 & No \\
\hline 14 & Positive & 3.5 & 0.13 & & 210 & No \\
\hline 15 & Negative & 1.6 & 0.29 & 4.7 & 120 & No \\
\hline 16 & Positive & 1.2 & 0.49 & 32.3 & 180 & No \\
\hline 17 & Negative & 0.9 & & 13.5 & 120 & No \\
\hline 18 & Negative & 1.6 & 0.9 & 3.5 & & Yes \\
\hline 19 & Negative & 1.3 & 0.05 & 11.6 & & Yes \\
\hline 20 & Positive & 1.2 & 0.1 & 20.4 & 240 & Yes \\
\hline 21 & Positive & 0.9 & 0.09 & 17.3 & 120 & No \\
\hline 22 & Positive & 1.0 & 0.25 & 3.9 & 210 & Yes \\
\hline Mean (SD) & & $1.2(0.6)$ & $0.16(0.13)$ & $14.2(8.1)$ & $182(43)$ & \\
\hline
\end{tabular}

gi, glucose intolerance. 
Six NASH patients (27\%) and seven control subjects $(30 \%)$ had equivocal tests and did not demonstrate a significant $\mathrm{H}_{2}$ and $\mathrm{CH}_{4}$ rise. This could be due to these individuals not being colonised by $\mathrm{H}_{2}$ or $\mathrm{CH}_{4}$ producing bacteria or having mouth to caecum transit times greater than the observation period of four hours. Small intestinal transit time could not be estimated in these 13 individuals. The mean small intestinal transit time for NASH patients and control subjects was 182 minutes and 180 minutes, respectively $(p=0.3)$. The mean small intestinal transit time for NASH patients with positive breath tests for SIBO was longer than that of control subjects (196 $v 180$ minutes; $\mathrm{p}=0.4$ ).

\section{LACTULOSE-RHAMNOSE INTESTINAL}

PERMEABILITY TESTS

Intestinal permeability data are presented in tables 2 and 3. The mean lactulose/rhamnose permeability ratio (L/R ratio) for $\mathrm{NASH}$ patients and control subjects were 0.16 and 0.13 , respectively $(p=0.37)$. The mean $L / R$ ratio for NASH patients with SIBO was higher than that of NASH patients without SIBO $(0.19 v 0.10 ; \mathrm{p}=0.13)$.

ENDOTOXIN LEVELS

Endotoxin levels are presented in tables 2 and 3. Mean endotoxin levels for NASH patients and control subjects were 1.2 and $1.3 \mathrm{EU} / \mathrm{ml}$, respectively $(p=0.5)$. Mean endotoxin levels were similar in NASH patients with and without $\operatorname{SIBO}(1.2 v 1.2 \mathrm{EU} / \mathrm{ml})$.

TNF- $\alpha$ ASSAY

TNF- $\alpha$ levels are shown in tables 2 and 3 . $\mathrm{NASH}$ patients had significantly higher mean TNF- $\alpha$ levels than control subjects (14.2 $v 7.5$ $\mathrm{pg} / \mathrm{ml}, \mathrm{p}=0.001,95 \% \mathrm{CI}$ for the difference between means $2.8-10.6 \mathrm{pg} / \mathrm{ml}$ ). NASH patients with SIBO on breath testing did not have statistically significant higher mean $\mathrm{TNF}-\alpha$ levels than NASH patients without SIBO (15.4 $v 12.4 \mathrm{pg} / \mathrm{ml} ; \mathrm{p}=0.4)$. In NASH patients there was no statistically significant correlation between $\mathrm{TNF}-\alpha$ values and endotoxin levels $(r=-0.3, \mathrm{p}=0.5)$, permeability $(r=0.3, \mathrm{p}=0.3)$, or alanine aminotransferase levels $(r=-0.3$, $\mathrm{p}=0.08)$. There was a statistically significant negative correlation between TNF- $\alpha$ values and BMI $(r=-0.5, \mathrm{p}=0.02)$.

\section{Discussion}

One of the major findings of this study was a significantly higher prevalence of SIBO in NASH patients compared with an age and sex matched control group. This is the first controlled study of NASH patients to document this association.

There are several possible explanations for an increased prevalence of SIBO in NASH. Diabetes, an important association of NASH, may predispose to SIBO due to intestinal dysmotility and stasis. However, diabetes or glucose intolerance was present in only a minority (5/11) of NASH patients with SIBO. Nevertheless, if the data are reanalysed and NASH patients with diabetes or glucose intolerance are excluded, there is no longer a significant difference in the prevalence of SIBO between the remaining NASH patients and control subjects $(46 \% v 22 \%, \mathrm{p}=0.13)$. It is possible therefore that an association between diabetes and SIBO could explain some of the increased prevalence of SIBO in the NASH group.

We were unable to find other predisposing causes to account for the increased prevalence of SIBO in our NASH patients. We could not detect any significant difference in small intestinal transit time between NASH patients and control subjects to suggest impaired intestinal motility. There was no immunodeficiency among NASH patients that could have predisposed them to SIBO. None had evidence of an isolated $\operatorname{IgA}$ or generalised immunoglobulin

Table $3{ }^{14} C-D$-xylose and lactulose breath tests, endotoxin levels, intestinal permeability, tumour necrosis factor $a(T N F-a)$ levels, small intestinal transit times, and diabetes prevalence for control subjects

\begin{tabular}{|c|c|c|c|c|c|c|}
\hline Patient No & $\begin{array}{l}{ }^{14} C-D-x y l o s e+ \\
\text { lactulose breath test }\end{array}$ & $\begin{array}{l}\text { Endotoxin } \\
(\text { EU/ml })\end{array}$ & $\begin{array}{l}\text { Intestinal } \\
\text { permeability }(L / R \\
\text { ratio) }\end{array}$ & $\begin{array}{l}T N F-\alpha \\
(p g / m l)\end{array}$ & $\begin{array}{l}\text { Small intestinal transit } \\
\text { time (minutes) }\end{array}$ & $\begin{array}{l}\text { Diabetes } \\
\text { (yes/no/gi) }\end{array}$ \\
\hline 1 & Negative & 1.2 & & 4.7 & 120 & No \\
\hline 2 & Positive & 1.4 & 0.06 & 16.2 & 120 & No \\
\hline 3 & Negative & 1.5 & 0.04 & 0.4 & 150 & No \\
\hline 4 & Negative & 1.4 & 0.15 & 9.7 & 240 & No \\
\hline 5 & Positive & 1.4 & & 10.8 & 270 & No \\
\hline 6 & Negative & 1.2 & 0.45 & 14.7 & 150 & No \\
\hline 7 & Positive & 1.2 & 0.04 & 7.3 & 180 & Yes \\
\hline 8 & Negative & 1.2 & 0.10 & & 90 & No \\
\hline 9 & Negative & 1.1 & 0.12 & 6.6 & 240 & No \\
\hline 10 & Negative & 1.3 & & 4.7 & & No \\
\hline 11 & Negative & 1.3 & 0.18 & 7.3 & 240 & No \\
\hline 12 & Negative & 1.0 & 0.08 & 3.1 & 180 & No \\
\hline 13 & Negative & 1.2 & & 8.1 & 150 & No \\
\hline 14 & Negative & 1.5 & 0.06 & 7.3 & & No \\
\hline 15 & Negative & 1.3 & & 9.3 & 240 & No \\
\hline 16 & Negative & 1.1 & & 14.3 & & No \\
\hline 17 & Negative & 2.0 & 0.16 & 5.4 & & No \\
\hline 18 & Negative & 1.7 & & 5.8 & 120 & No \\
\hline 19 & Negative & 0.9 & 0.18 & 6.6 & & No \\
\hline 20 & Negative & 1.3 & 0.08 & 6.2 & & No \\
\hline 21 & Positive & 1.2 & 0.11 & 3.5 & 210 & No \\
\hline 22 & Negative & 1.5 & 0.12 & 6.6 & & No \\
\hline 23 & Positive & 1.1 & 0.15 & 5.8 & 180 & No \\
\hline Mean (SD) & & $1.3(0.2)$ & $0.13(0.09)$ & $7.5(3.8)$ & $180(53)$ & \\
\hline
\end{tabular}

gi, glucose intolerance. 
deficiency (data not shown). Although an association between NASH and SIBO due to small intestinal diverticulosis has been described, we did not perform barium follow through examination as we felt barium studies in every patient was not clinically justified. None of our patients had a surgical blind loop.

A final possible explanation for the increased prevalence of SIBO in NASH patients could be achlorhydria. Achlorhydria was not formally assessed. Antisecretory agents may cause achlorhydria and predispose to SIBO. Only two $\mathrm{NASH}$ patients were receiving antisecretory medication, one of whom had a positive breath test. Six control subjects were using such medication at the time of study, three of which had positive breath tests. While antisecretory drug use may be an important predisposing factor to SIBO, the higher prevalence of SIBO in NASH patients cannot be attributed to higher antisecretory use in this group.

A pathogenic role for SIBO in NASH patients would be strongly supported by increased intestinal permeability and endotoxin and TNF- $\alpha$ levels in the subset of NASH patients with SIBO. We were unable to demonstrate a statistically significant difference in any of these parameters between NASH patients with and without SIBO. It is possible therefore that the finding of an increased prevalence of SIBO in our NASH patients was fortuitous and without pathogenic significance.

Disappointingly, we could not detect elevated endotoxin levels in NASH patients or NASH patients with SIBO. Endotoxin may still be an important factor in the pathogenesis of NASH as there may be several explanations for the negative result of this study. Firstly, sera for endotoxin levels were taken retrospectively rather than at the time of diagnosis. Retrospective collection of endotoxin may have underestimated endotoxin levels. Secondly, systemic levels may not be sufficiently sensitive to reflect portal endotoxin and it was not ethically possible to sample the portal circulation directly. Thirdly, "hidden" endotoxin, bound to plasma proteins, are not measured using the standard limulus amoebocyte lysate assay. "Bound" endotoxin can be measured. ${ }^{15}$ Using such techniques, endotoxin levels in alcoholic steatohepatitis have been shown to be $6-10$-fold higher than in healthy control subjects. ${ }^{16}$ It is possible that measurement of "bound" endotoxin fraction may have revealed a similar difference between our NASH patients and control subjects. Finally, it may be enteric bacterial products other than endotoxin which are important in the pathogenesis of NASH. Interestingly, metronidazole reversed steatohepatitis in humans after intestinal bypass and in rats with SIBO. ${ }^{16}$ Because of their sensitivity to metronidazole, Lichtman et al has implicated anaerobic bacterial species such as Bacteroides, rather than aerobic Gram negative bacteria such as $E$ coli from which endotoxin is derived, in the pathogenesis of hepatic injury associated with SIBO. Measurement of peptidoglycan-polysaccharide polymers, which are integral cell wall components of most bacterial species, would be an important future study.

TNF- $\alpha$ levels were twofold higher in NASH patients than control subjects $(p=0.001)$. This is the first controlled study to demonstrate elevated TNF- $\alpha$ levels in NASH patients. This finding supports the concept that $\mathrm{TNF}-\alpha$ plays a significant role in the pathogenesis of NASH as a "second hit" following the development of steatosis. ${ }^{1017}$ This finding may also provide indirect support for the role of endotoxin in the pathogenesis of NASH as TNF- $\alpha$ is the proven effecter of endotoxin liver injury. ${ }^{18} 19$ More direct support for endotoxin induced stimulation of TNF- $\alpha$ was lacking from this study as we were unable to demonstrate a statistically significant positive correlation between $\mathrm{TNF}-\alpha$ and endotoxin levels.

An association with obesity and elevated TNF- $\alpha$ levels has been described, ${ }^{20}$ and the relative obesity of our NASH patients is a possible explanation for the higher $\mathrm{TNF}-\alpha$ values of this group. Interestingly however, there is a statistically significant negative correlation between $\mathrm{TNF}-\alpha$ values and BMI in NASH patients. It is difficult therefore to attribute elevated $\mathrm{TNF}-\alpha$ values to obesity.

In summary, we found an increased prevalence of SIBO and higher TNF- $\alpha$ levels in NASH patients compared with control subjects. This was not associated with increased intestinal permeability or elevated endotoxin levels as we had postulated. The significance of our findings remain uncertain. The possible pathogenic role of SIBO in NASH could be further investigated by treating SIBO and assessing any improvement in NASH.

The authors are indebted to D Wigg (Department of Clinical Radiobiology, Royal Adelaide Hospital-statistics), E Southcott (Department of Gastroenterology, Adelaide Women's and Children's Hospital-intestinal permeability studies), and C Gray GroPep Pty Ltd-endotoxin assay).

1 Drenick EJ, Fister J, Johnson D. Hepatic steatosis after intestinal bypass-prevention and reversal by metronidazole, irrespective of protein-c
Gastroenterology 1982;82:535-48.

2 Kim WR, Poterucha JJ, Porayko MK, et al. Recurrence of non-alcoholic steatohepatitis following liver transplatation. Transplantation 1996;62:1802-5.

3 Nazim M, Stamp G, Hodgson HJF. Non-alcoholic steatohepatitis associated with small intestinal diverticulosis and bacterial overgrowth. Hepatogastroenterology 1989;36:34951

4 Lichtman SN, Sartor RB, Keku J, et al. Hepatic inflammation in rats with experimental small intestinal bacterial overgrowth. Gastroenterology 1996;98:414-23.

5 Freund HR. Abnormalities of liver function and hepatic damage associated with total pareteral nutrition. Nutrition 1991;7:1-5.

6 Lichtman SN, Keku J, Schwab JH, et al. Hepatic injury associated with small bowel bacterial overgrowth in rats is prevented by metronidazole and tetracycline. Gastroenterolprevented by metronidaz

7 Pappo I, Bercovier H, Berry EM, et al. Polymyxin B reduces total parenteral nutrition-associated hepatic steatosis by its antibacterial activity and by blocking deleterious effects of ipopolysaccharide. FPEN $\mathcal{F}$ Parent Enteral Nutr 1992;16: 529-32.

8 Thurman RG, Bradford BU, Knecht KT, et al. Endotoxin, Kupffer cells and alcoholic liver injury. Gut and the liver. Falk symposium 1997;100:222-40.

9 Bode C, Schäfer C, Bode JC. The role of gut derived bacterial toxins (endotoxin) for the development of alcoholic liver disease in man. Gut and the liver. Falk symposium 1997;100:281-98.

10 Yang SQ, Lin HZ, Lane MD, et al. Obesity increases sensitivity to endotoxin liver injury: implications for the tivity to endotoxin liver injury: implications for the
pathogenesis of steatohepatitis. Proc Natl Acad Sci USA pathogenesis of steat 
11 King CE, Toskes PP, Spivey JC, et al. Detection of small intestine bacterial overgrowth by means of a ${ }^{14} \mathrm{C}$-D-xylose

12 Lewis JL, Young G, Mann M, et al. Improvement in the specificity of $\left[{ }^{14} \mathrm{C}\right] d$-xylose breath test for bacterial overgrowth Dig Dis Sci 1997;42:1587-92.

13 AGA technical review on the evaluation and management of chronic diarrhea. Gastroenterology 1999;116:1464-86.

14 Miki K, Butler R, Moore D, et al. Rapid and simultaneous quantification of rhamnose, mannitol, and lactulose in urine by HPLC for estimating intestinal permeability in paediatric practice. Clin Chem 1996;42:71-5.

15 Bode C, Fukui H, Bode JC. "Hidden" endotoxin in plasma of patients with alcoholic liver disease. Eur $\mathcal{F}$ Gastroenterol Hepatol 1993;5:257-62.
16 Tarao K, So K, Moroi $\mathrm{T}$, et al. Detection of endotoxin in plasma and ascitic fluid of patients with cirrhosis: its cliniplasma and ascitic fluid of patients with cirrhosis:
cal significance. Gastroenterology 1997;73:539-42.

17 James O, Day C. Non-alcoholic steatohepatitis: another disease of affluence. Lancet 1999;353:1634-6.

18 Mohler K, Sleath P, Fitzner J. Protection against a lethal dose of endotoxin by an inhibitor of tumour necrosis factor processing. Nature 1994;370:218-20.

19 Ashkenazi A, Marsters A, Capon D, et al. Protection against endotoxic shock by a tumour necrosis factor receptor immunoadhesin. Proc Natl Acad Sci USA 1991;88:10535-9.

20 Winkler G, Salomon F, Harmos G, et al. Elevated serum tumour necrosis factor-alpha concentrations and bioavailability in type 2 diabetics and patients with and 